\title{
What is outside? The Early Years Foundation Stage in England: Outdoor Facilities, Organisation and Staff Attitudes
}

\author{
Helen Bilton* \\ Institute of Education, University of Reading, Reading, England \\ *Corresponding author: h.o.bilton@reading.ac.uk
}

Received September 19, 2014; Revised October 19, 2014; Accepted October 22, 2014

\begin{abstract}
The purpose of this paper is to report on the facilities available, organisation of, and staff attitudes to early years outdoor education from schools within the south east of England, focusing on provision for children aged three to five. One component of the successful education of the child involves providing an 'environment for learning', including the facilities, layout and routines. This paper presents findings concerning the type and variety of facilities available outside; the various styles of organisation of the space; staff attitudes about: their roles, their aims for the environment, children's behaviour and learning, and perceived drawbacks to practice. This paper draws on empirical data collected from schools within the University of Reading partnership. The findings suggest that although all early years settings must adhere to the statutory framework there are a range of facilities available, and there are a number of ways this environment is organised. Further there appears to be uncertainty about the adult role outside and the aims for activities. The conclusions drawn indicate that staff do not appear to be linking their aims for outdoor education to the facilities provided or to their actions outside. This means there is not a clear link between what staff provide outside and the declared ambitions for learning. This study is important as all educators need to be certain about their aims for education to ensure best outcomes for children. The implications of these findings for early years teachers are that they need to be able to articulate their aims for outdoor education and to provide the correct facilities to achieve these aims. Finally this study was undertaken to raise debate, posit questions and to ascertain the parameters for further research about the early years outdoor environment.
\end{abstract}

Keywords: outdoor environment, early years, facilities, play, staff attitudes, aims

Cite This Article: Helen Bilton, "What is outside? The Early Years Foundation Stage in England: Outdoor Facilities, Organisation and Staff Attitudes." American Journal of Educational Research, vol. 2, no. 10 (2014): 942-949. doi: 10.12691/education-2-10-14.

\section{Introduction}

Any educational setting has to provide an environment in which learning and teaching can take place. For this environment to effectively support learning and teaching it has to be organised and managed to fit the needs of the children. However, it would appear that teachers can be unclear about not only what to provide in the early years outdoor environment but also why something is being provided. It was decided to carry out this piece of research to ascertain whether what was being provided had any pedagogical grounding and what the pedagogical implications were for decisions made concerning the outdoor early year teaching and learning environment. By gathering this data I was wanting to reveal the pedagogical implications of the facilities we provide and the organisation we offer.

\section{Literature Review and Conceptual Framework}

\subsection{Traditions}

Nursery/early years education in England has been privy to traditions $[1,2,3,4]$. That is, conventions which have grown up over time and are now expected. One of these traditions has been the provision of an outside area. An area not viewed as a school playground for children and staff to have a break but as a teaching and learning space similar to the indoor classroom. Alongside these conventions have grown traditions about how the staff should act - which has come to be described as 'best practice' [5]. This concentration on 'best practice' and teacher action has arisen as a result of early years education being significantly different to statutory education and with a belief that the difference has to be explained. However, the danger of education being shaped by 'best practice' is that it does not provide opportunities to understand the basic principles of the practice [5]. This perceived lack of pedagogical understanding within early years education has been discussed by various authors including Stephen, Rogers, Siraj-Blatchford et al [5,6,7]. Writers such as Browne, Eaude, Stephen and Waller $[5,8,9,10]$ have furthered this debate by considering the 
negative outcome of focusing on practice, described by Browne as 'the truths' [8]. Rogers looking at play and pedagogy in the reception class suggests early years practice still starts not from the needs of the child but from 'the persepctive of the adult's role in providing an environment and strategies that support the processes of teaching and learning' [[5], pp. 2]. An understanding of the theories underlying the practice for the most part is missing, and indeed, in the Stephen study, staff 'found it difficult to answer 'why' questions' [[5], pp.228].

\subsection{Facilities and Organisation}

Part of 'best practice' describes the facilities, the layout of the space, and daily routines. This is defined by Bilton [11] as the environment for learning and by SirajBlatchford et al [7] as the 'pedagogical framing', or the 'behind the scenes' work to support the teaching and children's learning (pp. 8). Both argue that this 'pedagogical framing' has a strong bearing on the outcomes for children. The Effective Provision of Preschool Education (EPPE) study has demonstrated the ability to accurately gauge quality through the measurement of the environment using observational instruments. The EPPE team used the Early Childhood Environment Rating Scale (ECERS) devised in 1980 and updated in 2005 [12] to measure the quality of settings in England. They also devised an extension rating - the Early Childhood Environment Rating Scale -Extension (ECERS-E) to supplement the ECERS, including four new sub scales [13]. ECERS-R measures space and furnishings, personal care routines, language-reasoning, activities, interaction, programme structure, and parents and staff [12] and ECERS-E measures literacy, mathematics, science and diversity [14]. Importantly, for this present study, and the reason for sharing these rating scales is to demonstrate that the quality of the setting can be measured through rating facilities and action and that the results of the EPPE research, for example, demonstrates that facilities and action do impact on children's development.

In terms of facilities, the early years tradition declares that the space outside will have particular resources to fulfil certain developmental needs. For example, within this tradition children will need to have access to movement on a large scale including climbing, access to construction and building materials including sand, the opportunity to investigate and experience the natural world and the chance to play with others and practise skills involving confidence building [3,11,15,16,17,18,19]. These traditions can be traced back through early years writers, including Cusden, de Lissa, Isaacs, McMillan and Owen [20-24]. Some of the expectations became quite prescriptive in some authorities. For example, in the 1980s the Inner London Education Authority gave each school a list of exactly what facilities should be provided in all of their nursery gardens, including planks and a barrel in a metal frame [25]. More recently however, there has been a marked change in the facilities provided outside. This could be linked to a greater Governmental interest in the early years sector, the huge growth in private providers and the lack of a workforce fully knowledgeable about early years education. For example there has been a growth in the large static climbing frame, whereas the tradition had been for a moveable climbing frame which could be sited in the most appropriate spot depending on the weather. Likewise, the three wheeler tricycle and plastic car are almost universally found in outdoor areas now, but not 30 years ago. These types of vehicle encourage individualistic behaviour whereas trucks which were the expected norm encourage cooperative play, including talk. With the previous Government's push on early years' education came the growth in children's centres but also a growth of Foundation Stage units with a large number of children being educated together and often sharing one outdoor area, whereas previously, nursery schools with their specialised knowledge had provided education for a large number of children. At this juncture it is important to ask: is the driver for these traditions and changes, children's developmental needs linked to pedagogy or have these changes simply occurred without forethought or planning?

With these thoughts in mind two research questions were devised:

What facilities are available in early years outdoor environments and what are staff's attitudes to various aspects of outdoor practice?

What are the pedagogical implications of these choices?

\section{Research Methods}

\subsection{Data Collection}

Data was collected via an online survey to 350 maintained schools with early years provision in the University of Reading partnership. Contact was initially to the administrative address of the school and when there was no response this was followed up with telephone and email contact to named teachers. The reliability of the survey was tested on a small pilot of eight schools who offered feedback on the survey design. Piloting enabled me to ensure questions had clarity and relevance and could not be open to interpretation. Questions were both closed and open ended, some graded and some multi choice. Some were quite specific, for example asking whether the school ran a free-flow or timetabled approach. Some needed a clear measurement answer, for example, how long the outdoor area was available to children in one session or what the size of the space was. Some were highly open - ended, for example, asking what the schools aims for outdoor activities were or what they saw as the adult's role outside. A survey was chosen very specifically as I was trying to quickly and simply gain a picture of as many settings as possible, this was not trying to gain a comparison but a view of what was available and what staff thought.

The survey was entitled: 'Early Years Foundation Stage - facilities and staff behaviours and attitudes'. The questions aimed to elicit what facilities settings actually had, what staff felt about certain issues and what they said they did in practice. However, it has to be acknowledged that the replies were written and as action was not observed, the answers could only be construed as a 'behavioural indicator of an attitude' [[26], pp.209].

\subsection{Sample}

All the schools were in the maintained/state sector and none were from the private sector. All had to adhere to the 
Statutory framework for the early years foundation stage [27]. Of the 350 schools contacted, 184 completed the survey, giving a response rate of 53 per cent. A broad convenience sample (geographically and by association) was chosen to ensure a good response rate, in a short time scale and to ensure an easy route for follow up work. All of these schools worked with the University of Reading to train teachers and were aware that the findings would be disseminated to support them further in developing their own outdoor provision. The range of educational settings included small rural schools, urban and community schools, small and large nursery schools, children's centres, large and small primary schools and infant schools with a range of cultures and languages. They all provided for children aged three to five years of age. The schools were within eight local authorities and 65 per cent of the schools were primary, 23 percent infant, 9 percent nursery schools, 1 percent special schools and 2 per cent did not declare their school name or type. Only the teacher in charge of the class or unit, or in the case of nursery schools, the headteacher, completed the questionnaire. This was the first step of my study and I wanted to gather a snap shot of facilities and attitudes regardless of experience or qualification. The next step is to narrow down the sampling to specific types and groups.

\subsection{Data Analysis}

The online survey included closed and open ended questions. The survey was analysed in SPSS with frequencies and cross tabulations used to explore the data. Using frequencies allowed an overall picture of the data, cross tabulation enabled exploration of patterns. The categorization of the information volunteered in the replies to the questions was imposed retrospectively after careful consideration of what individuals had written. Thus inductive, open, 'free' coding was applied. 'Coding refers to the ongoing process of assigning conceptual labels to different segments of data in order to identify themes, patterns, processes and relationships' [[28], pp. 87]. This type of analysis was explicitly employed as I wanted to 'build theory from data rather than testing existing theories' [[28], pp. 99]. Themes emerged as a result of the process of systematic coding and, as the analysis and comparison of data continued, some of the initial codes were combined into broader categories. No respondent was coded twice for the same theme. The responses were looked at from the standpoint of a researcher and early years teacher with advanced knowledge of the early years outdoor environment. Both the usual and unusual themes were identified and considered alongside the research evidence. In carrying out this research full ethical clearance was sought and granted from The University Research Ethics Committee and all ethical procedures and guidelines were complied with. In reporting the data, all identifying information has been removed.

\section{Results}

\subsection{What Facilities are Available in Early Years outdoor Environments, and What are Staff Attitudes to Various Aspects of Outdoor Practice?}

\subsubsection{Number of Classes and Children}

In some schools the outdoor environment could be accessed by a number of classes and children. The most common number of classes accessing outside was two (34.9 per cent of the total respondents), with two and three classes making up nearly two thirds of the respondents reply. Nearly a fifth of the respondents indicated that four classes could access the outdoor space. If this data is then viewed alongside the number of children accessing outside at any one time, this could be anywhere between under 10 and over a 100 (See Table 1).

Table 1. Number of children able to access the outdoor area at any one time

\begin{tabular}{|c|c|}
\hline Number & Frequency \\
\hline Up to 10 & 1 \\
\hline $11-20$ & 12 \\
\hline $21-30$ & 31 \\
\hline $31-40$ & 18 \\
\hline $41-50$ & 18 \\
\hline $51-60$ & 47 \\
\hline $61-70$ & 9 \\
\hline $71-80$ & 7 \\
\hline $81-90$ & 14 \\
\hline $91-100$ & 2 \\
\hline More than 100 & 16 \\
\hline Total & 175 \\
\hline Missing & 9 \\
\hline Total & 184 \\
\hline
\end{tabular}

The most common number of children accessing outside at any one time was 51-60 children (47 respondents, 26.9 per cent of the total replies). Nearly a tenth had more than a 100 children who could access the area at any one time. The standard class size is 30 children and yet 131 respondents (75 per cent of the total) indicated that the outdoor area was accessed by between 31 and over a 100 children and over a fifth of respondents suggested their space could be accessed by more than 71 children. This suggests a much more playtime approach than a learning environment. However, the time allowed outside does not mirror a primary playtime with 54 per cent indicating that children were allowed out for up to three hours in a session, whereas the standard playtime is 20 minutes and lunch break one hour, which includes eating lunch (See Table 2). When the number of children is cross tabulated with whether staff felt the space was an effective size, there was a trend towards those with fewer children indicating that the space was too small or that the layout was problematic.

Table 2. Maximum number of children able to access the outdoor area and for what period of time

\begin{tabular}{|c|c|c|c|c|c|c|}
\hline & Number of Children & $1-20$ & $21-30$ & $31-70$ & 71-100 plus & Total \\
\hline \multirow[t]{4}{*}{ Length of time } & Up to an hour & 3 & 8 & 10 & 3 & 24 \\
\hline & Up to 2 hours & 5 & 9 & 28 & 15 & 57 \\
\hline & Up to 3 hours & 5 & 14 & 53 & 22 & 94 \\
\hline & Total & 13 & 31 & 91 & 39 & 174 \\
\hline
\end{tabular}


This range of responses can be reflected in the description of three outdoor spaces all within three miles of each other. School A is a community based primary school with a 20 place early years class. In total it has an area of 160 square metres. Out of this total area is taken the space for a gas metre, fire stairs, outside entrance with disabled access and entrance to the nursery, which leaves 145 square metres. The main gates and high brick wall make up two sides of the rectangular. The fixed equipment includes garden boxes, sandpit, house, chalk board and boat. In contrast school B, a 45 place foundation class, part of a large suburban school, has 240 square metres available, and has both tarmac and soft surfaces. Again it has a large fixed disabled access which reduces the space, leaving 220 square metres. Fixed equipment includes a sandpit, house, musical instruments, flower tubs, seat around a tree, climbing frame, two water trays, 3 sheds and chalk boards. Finally school $\mathrm{C}$ is a Foundation Stage unit attached to a primary school and caters for 104 children. It has 1356 square metres available, including tarmac, soft surface, and grass. Space available to children is reduced as there are two large storage units in the centre of the area, leaving 1284 square metres. Fixed equipment includes a climbing frame, two houses, plant tubs and in fact this environment has trees and shrubs. The space is around the building and narrows quite dramatically down one side. The largest space has the least amount of fixed equipment, and although a more difficult space to manage has more flexibility than the other two. So roughly school A has seven square metres of space available per child, school B has five square metres available per child and school $\mathrm{C}$ has 12 square metres.

\subsubsection{Facilities}

Respondents were asked what fixed equipment they possessed, there were a total of 382 responses with respondents able to note any number of pieces of equipment. The most common response as to what fixed pieces of equipment schools had were gross motor (that is some form of climbing apparatus, including tunnels, bridges, climbing walls, monkey bars and the more standard climbing frame). Of the 126 answering the question, 72, that is nearly 6o per cent of the respondents indicated they had this type of equipment. The second most common was some form of play house with 69 respondents, and this accounted for just over half of the respondents. This was closely followed by 64 of the total 126 respondents signally they had a fixed sandpit (50.8 per cent). The fourth most popular item was some form of fixed vehicle (such as a boat, ship or train) with 27 respondents. There were 11 respondents (8.7 per cent) who indicated they didn't have any fixed equipment. The percentage of responses for other equipment was quite low in comparison, and included a stage, musical instruments, growing boxes, fixed water play and swings. Finally, 18 respondents (14.3 per cent) indicated they had tables for writing, reading and mathematical activities.

When the coded responses were further merged the following categories were revealed: fixtures and fittings, understanding of the world and science equipment (sand, water, soil), subject based activities (music, maths, English), imaginative play facilities and gross motor equipment (See Table 3). This clustering indicated that in fact equipment fostering gross motor development was less prevalent (78 respondents) than facilities which aid imaginative play (116 respondents) and understanding of the natural world and science (103 respondents). Subject based facilities accounted for 22.2 per cent of respondents.

Table 3. Types of fixed equipment

\begin{tabular}{|c|c|c|}
\hline Types of equipment & $\mathrm{N}$ & Percent of cases (184) \\
\hline Fixtures and fittings (shed, shelter, seating) & 39 & $30.9 \%$ \\
\hline Understanding of the world and science (sand, water, soil, plants) & 103 & $81.8 \%$ \\
\hline Subject based activities (music, maths, English) & 28 & $22.2 \%$ \\
\hline Imaginative play ( vehicle, house, stage) & 116 & $92.1 \%$ \\
\hline Gross motor (including swing) & 78 & $61.9 \%$ \\
\hline None, unspecified & 15 & $11.9 \%$ \\
\hline Moveable & 3 & $2.4 \%$ \\
\hline Total & 382 & $303.2 \%$ \\
\hline
\end{tabular}

Respondents were asked about the number of threewheeler/tricycles they possessed. There were 119 responses. Of these 42 per cent indicated they had one to five three -wheelers/tricycles and 58 per cent indicated they had 5 or more three - wheelers, with seven respondents indicating they had up to 15 three - wheelers and one respondent noting they had over 20. Only eight respondents indicated they had no three - wheelers. So the majority of respondents had three - wheeler bicycles.

\subsubsection{Behaviour and Learning}

Respondents were asked whether they considered the behaviour and learning of children to be different outside as compared to inside. Of the 124 respondents who answered the question concerning learning 68.5 per cent felt learning was different outside compared to in. Of these 83 went on to explain why. Concerning behaviour, 92 per cent of the 127 respondents felt children's behaviour was different outside compared to in and of those 113 offered reasons as to why. It would appear more respondents were willing to discuss behaviour rather than learning.

In terms of learning 51 respondents (63 per cent) described the approach to learning as being more positive and meaningful: children were freer, more confident, more exploratory, and that the opportunity to talk was more available than inside (See Table 4). Just under half of the respondents mentioned that outside children could partake of more physical activity, which was on a larger scale, and could be both noisier and messier than inside. Child initiated play was seen as a difference inside to out by 16 per cent of respondents. Other comments included the outside giving more opportunity to explore the natural environment, and that it was an important space for the learning of boys. 
Table 4. Difference in learning outside compared to inside

\begin{tabular}{|c|c|c|}
\hline Types of learning & N & Per cent of cases (184) \\
\hline Freer, more exploration. more confident, more engaged, more meaningful experience, more risk taking, more talking & 51 & $63.0 \%$ \\
\hline Child initiated & 13 & $16.0 \%$ \\
\hline More physical, active, larger scale, noisier, messier & 39 & $48.1 \%$ \\
\hline More opportunity to explore natural environment & 9 & $11.1 \%$ \\
\hline Important for boys & 4 & $4.9 \%$ \\
\hline Environment is different no explanation & 3 & $3.7 \%$ \\
\hline Negative comment about space & 2 & $2.5 \%$ \\
\hline Total & 121 & $149.4 \%$ \\
\hline
\end{tabular}

Of those 113 respondents who went onto discuss in what ways they considered children behaved differently outside, 64 respondents (56.6 per cent) felt that children's behaviour was more active outside in comparison to inside and just under half felt that children's approach and attitude was more positive outside in comparison to inside (See Table 5). Other comments included children being louder and more vocal, better behaved and more cooperative, and they had more conversations. Just under one fifth felt the outside had a negative impact on behaviour. Boys' behaviour outside was commented on by 14 respondents (12.4 per cent of the total). Almost all those who felt children's behaviour was poor outside also commented that learning outside was different in that it was child initiated, freer and more physical.

Table 5. Difference in behaviour outside compared to inside

Table 5. Difference in behaviour outside compared to inside
\begin{tabular}{|c|c|c|}
\hline Types of behaviour & $\mathrm{N}$ & Per cent of cases (184) \\
\hline More positive approach and attitude & 52 & $46.0 \%$ \\
\hline More active & 64 & $56.6 \%$ \\
\hline Boys mentioned & 14 & $12.4 \%$ \\
\hline Louder and more vocal & 31 & $27.4 \%$ \\
\hline Negative impact & 21 & $18.6 \%$ \\
\hline Better behaved, more cooperative & 20 & $17.7 \%$ \\
\hline More conversation & 6 & $5.3 \%$ \\
\hline Total & 208 & $184.1 \%$ \\
\hline
\end{tabular}

\subsubsection{Roles}

There were 122 respondents, just over two thirds of all respondents who replied to the question asking what teachers felt their roles were outside. Five categories were coded. The majority, 112 respondents, just over 90 per cent, saw their role as facilitating, supporting, developing, enhancing, scaffolding, interacting and engaging with children. A fifth of the total respondents (25) saw their role as developing oral language. Just over a third mentioned their role as being one to do with safety, therefore supervising children and a third of the respondents saw their role as that of observing children. Only nine respondents ( 7.4 per cent) mentioned explicitly the role was about teaching.

\subsubsection{Drawbacks to Practice}

Respondents were asked to comment on what factors created drawbacks to practice, with opportunity to tick as many of the eight suggestions as they wished. Just over half of the respondents mentioned the weather as a drawback to practice. The lack of storage facilities impacting negatively on practice was noted by 78 of the responses (52.7 per cent of the respondents). When asked if they would like to comment on drawbacks not listed, 67 respondents did. The most common was about a lack of staff and too many children for the number of staff, this was cited by 22 respondents (32.8 per cent). Insufficient resources, including lack of the appropriate surfaces, and inappropriate equipment was considered to have an impact on practice by 19.4 per cent of respondents (13 schools). Additional drawbacks but related to the weather were flooding and muddy areas (10.4 per cent respondents), lack of shelter (9.0 per cent respondents), and the impact of the weather on both inside and out (6.0 per cent of respondents). A fifth of the respondents however, felt their area did not have any drawbacks. The survey asked about the effectiveness of the space size and there were 128 respondents. Of those, 102 respondents (79.2 per cent) said yes the space was an effective size and 24 (18.8 per cent) said no and two (1.6 per cent) did not know. A number (55) of teachers volunteered further information and of these 25 felt the space was effective although some did go on to comment about problems, which included the space being too small or too large, to those wanting grass to those having too much grass and those needing a covered area and those identifying layout issues.

\subsubsection{Aims}

While some respondents were able to explain what the aims of outdoor activity were, a significant number were unable to identify aims; again, a significant number did not distinguish between approach/practice and aims (See Table 6). Under half of all the respondents (80 of 184) were able to offer aims and, of those 80 , half (40) offered one aim [29]. So not only were there fewer teachers who could offer aims than those that did not; even those that did, offered only a very small number. Of the 15 coded responses identified in this research pertaining to aims, nine could be described as the action of practice, not the aims. These included real world experiences, open access to resources, gender and role play.

Table 6. Frequency of coded responses identifying aims

\begin{tabular}{|c|c|}
\hline Aims & $\mathrm{N}$ \\
\hline Physical development & 57 \\
\hline Dispositions for learning/personal development & 35 \\
\hline $\begin{array}{c}\text { Exploration of the natural world, scientific and environmental } \\
\text { study }\end{array}$ & 22 \\
\hline Social development & 14 \\
\hline Oral language & 8 \\
\hline Mathematics and literacy & 8 \\
\hline Individual needs & 22 \\
\hline Gender and outside & 3 \\
\hline Role play & 19 \\
\hline Open access to resources & 9 \\
\hline A different environment & 14 \\
\hline Statutory Guidance & 7 \\
\hline Real world experiences & 3 \\
\hline Aims same as for inside & 58 \\
\hline No relevant theme to emerge & 8 \\
\hline Total & 287 \\
\hline
\end{tabular}




\section{Discussion}

\subsection{What are the Pedagogical Implications of these Findings?}

What school staff do, and how they act will reflect their own value system [30]. If we take for example, risk and challenge, Sandseter [31,32] demonstrates, through her own research and the gathering of all relevant literature that the values of the adults involved with children will impact on whether they allow or do not allow children to take part in risky play. As Waller and colleagues summarise, whether we allow risk or not, depends on our view of the child and whether we view the child 'as competent rather than as vulnerable and in need of adult protection' [[10], pp. 441]. Our view will impact on what we offer, what facilities we provide and how we manage the space, and as the EPPE findings demonstrate these things matter. However, some staff actions and facilities provided may not be within their ability to influence as they have been imposed. But those imposed facilities will still have implications for pedagogy. It is to a discussion about the possible pedagogical implications of the facilities and organisation and attitudes to the outdoor space I now turn.

\subsubsection{Classes and Children}

From the findings of this study the number of classes and number of children able to access the space is surprisingly varied. The possible consequences of this variety are the inability to provide access to a holistic curriculum in a small space with a small number of children, to the other end of the spectrum and having a playtime atmosphere rather than a teaching environment when there are a large number of children in the space. Further implications with a large number of children may be that staff consider they have to supervise rather than educate children or that assessment and tracking become overriding in comparison to teaching. It would seem that the number of children outside is a matter not of developmental need but of space allocation and whether a setting has decided to combine classes accessing the same space outside.

\subsubsection{Facilities}

From the results of the survey it would seem unsurprising that equipment which enhances gross motor development was common and the most popular. However, when the categories of fixed equipment are further grouped it is noteworthy that those pieces of equipment which would support cognitive and oral language development, for example role play, and understanding of the natural world and scientific understanding are the most prevalent. Gross motor development is the most common aim and oral language development the least. But these two findings seem to suggest a mismatch between what is being provided and the aims of the space. Or is it, that staff are assuming oral language development is happening through the social aspect of play and doesn't need to be highlighted? The facilities provided by schools do call into question why schools have the facilities they do. Why do so many schools have, for example, sandpits? Where is the link to the aims for a material which provides many scientific and mathematical opportunities? Most schools have three wheeler bikes, not to have them is highly unusual. However, when discussing the aims there are no references to these toys nor outcomes for them. It is unclear why these toys are in early years classes.

\subsubsection{Learning and Behaviour}

That behaviour and learning was considered different inside compared to out would fit the Stephenson [32] research which found children and staff's views to the two spaces quite different.

That learning outside was considered to be more physical and on a larger scale is not unexpected. However, what is illuminating are the findings from the comparison of data. Many teachers struggled to reveal aims but where they did physical development was seen as the most common aim. This finding, coupled with the evidence that more respondents were willing to discuss behaviour rather than learning, and finally that the majority of equipment concerned oral language development and understanding of the natural world could support the idea that staff are uncertain as to the purposes of the outdoor space or as to what is going on outside.

That nearly half of the respondents considered children had a more positive approach and attitude and were freer, more exploratory and confident outside could be seen as a positive. This would fit the aims responses in that the second most common aim for outside was developing the dispositions for learning. But this finding also has implications for inside in that it might be suggesting that inside is not seen as exploratory and freer and cannot allow for engagement and risk taking. This response possibly says more about the practice inside than outside. That there was a correlation between those who saw behaviour as poorer outside than in and the learning being freer, more child initiated and more physical outside suggests that some staff may not be familiar with how to facilitate learning through play.

\subsubsection{Roles and Drawback to Practice}

When looking at the data concerning roles outside, 20 per cent of staff suggested one of their roles concerned oral language development. Another separate coding indicated many saw their role was to: facilitate, support, develop, enhance, scaffold, interact and engage. All of these adjectives are likely to involve conversation with children. Therefore, one could suggest that over half of the respondents mentioned oral language directly or indirectly. And yet when looking at the aims data it is apparent that oral language development is rated very low in comparison to other aims put forward [29]. So although teachers may see their role as involving oral language development they do not appear to link it to aims for children's learning. Are teachers clear about what the terms they proffer mean in practice? Are they clear as to how 'facilitate' is different to 'enhance'? Are they clear as to whether 'support' is different to 'enhance'? A small number of teachers indicated their role involved teaching. If we are unable to identify that we are teaching and the aspects of teaching within play, are we in danger of, as Van der Eyken [34] suggested failing to 'place emphasis where it belongs - on educational needs' ([16], pp. 19).

Although weather is so much part of the outdoor experience, it was seen as a drawback to practice (59 per 
cent of respondents). One of the key aims suggested in the survey was the exploration of the natural world, so there appears a mismatch between that and that over half the respondents indicated the weather was a drawback to practice. Could it be it was not the weather but lack of suitable clothing, timetabling issues, or lack of staff interest in the outside that caused staff to suggest weather was a drawback? Some drawbacks to practice are likely to be out of teachers' control. For example that the area was prone to flooding and became muddy, that the layout and size of the space were problematic, or there was no storage, all seem to indicate issues caused by others: builders, designers and architects. Bilton [35] and McNee [36] argued that the rise in nursery classes within primary schools instead of providing nursery education in schools meant attention was taken away from the garden to simply finding a suitable classroom not a suitable garden and classroom. They argue this accounts for a rise in inappropriate early years gardens. In 1998 the Labour Government began a programme of increasing the number of early years places and in particularly embarked on a programme of building children centres. However, more often than not greater regard was given to the inside space and much less attention was given to the outdoor space and this was particularly so when the head of the centre was neither a teacher or an early years teacher.

A significant drawback to practice was considered the lack of staffing and too many children for the space- a third of respondents commented on this. This would fit with those who suggested the space was too small. This also links to replies which suggested that one of the staff roles is supervision. Again there is a mismatch between the use of the space and what then can be achieved. If you want children to write you need to provide the materials (eg: paper and pencils) but you also need to provide the stimulus (learning experiences).

\subsubsection{Aims}

That many respondents were unable to identify aims or identify only a very small number suggests a possible insecurity with the purpose of the outdoor space. Further, this lack of understanding seems to be supported by the responses concerning the facilities and attitudes, which at times do not match the aims. For example, language and mathematical development were not highlighted as significant aims, and yet within the roles responses, a fifth of the respondents felt the development of oral language was part of the adult's s role and within the equipment question over 90 percent of the facilities were geared to imaginative play which by its very nature has to involve oral language. Interestingly, music received no reference in the aims section and yet in terms of facilities, 7.9 per cent of respondents revealed they had musical instruments outside.

\section{Conclusion}

The purpose of this study was to report on the early years outdoor facilities, organisation and teacher attitudes in schools in the University of Reading partnership. Although often there is discussion in texts about best practice and approach, there is a clear gap in the literature concerning actual evidence of what schools have outside.
Hopefully this study has gone some way towards addressing this gap. It was also the intention of this study to discover whether there was a clear link between what facilities schools have and what the staff then consider is the purpose of those facilities. It would appear from this study that staff may not be linking aims, facilities provided and their actions outside. On the surface staff suggested outside was more to do with gross motor and physical development and yet when the facilities provided are looked at more closely there are more available to do with cognitive and oral language development. When looking to their roles, respondents saw one of them as developing language and yet the aims for the space do not indicate this. Some staff seemed to consider the freer approach outside may be linked to poor behaviour but it could be some staff are unsure as to how to develop this learning environment. Some aspects of the outdoor environment appeared to be outside the control of staff, for example the number of children accessing the space, the layout and shape, the propensity to flood. The huge variety in design and number of children accessing outside indicates a lack of understanding about possible optimum size, shape and so on. It is noted throughout this study that staff may not be making a clear link between facilities provided and aims and that the driver for the facility choices may have little to do with children's developmental needs linked to pedagogy. For example, the sandpit, a traditional facility, is often provided but do staff see the link to developing scientific understanding? The increase in non -traditional toys including bubble cars and three - wheeler tricycles may be to do with the increase of the private sector into early years provision. The increase in static facilities especially climbing frames may be related to teachers and pupils' everyday experience in the form of being taken to the park and there being an expectation that the outdoor environment will mimic this familiar space.

This research suggests the need for discussions about a number of issues, for example, has there been the necessary discussion about the purpose of a sandpit, the house or the three- wheeler bike? Are staff sufficiently aware that any organisation or facilities will say something about the teacher's pedagogy and will raise pedagogical issues? Do staff make a link between what they provide, how they act and the aims for education? The evidence and cross tabulation presented here suggests there is a disconnect between staff action and attitudes and facilities provided. Staff need to be cognisant of the implications of the 'third pedagogue' or the environment for learning to ensure good outcomes for children.

\section{References}

[1] Clift, P., Cleave, S., and Griffin, M., The aims, role and deployment of staff in the nursery. A report of the national foundation for educational research in England and Wales, NFER Publishing Company Limited, Windsor, 1980.

[2] Pound, L., “The Nursery Tradition,” Early Child Development and Care, 28, 79-88, 1987.

[3] Tovey, H., Playing outdoors. Spaces and places, risk and challenge, Open University Press, Maidenhead, 2007.

[4] Webb, L., Purpose and practice in nursery school, Oxford, Blackwell, 1974.

[5] Stephen, C., "Looking for theory in preschool education," Studies in philosophy and education, 31, 227-238, 2012. 
[6] Rogers, S., Rethinking play and pedagogy in early childhood education, Routledge, Abingdon, 2011.

[7] Siraj- Blatchford, I., Sylva, K., Muttock, S., Gildren, R. and Bell, D., Researching effective pedagogy in the early years research report RR356, Department for Education and Skills, London, 2002.

[8] Browne, N., Gender equity in the early years, Open University Press, Maidenhead, 2004.

[9] Eaude, T., Thinking through pedagogy for primary and early years, Learning Matters Ltd, Exeter, 2011.

[10] Waller, T., Sandseter, E., Wyver, S., Arlemalm-Hagser, E., and Maynard. T., "The Dynamics of Early Childhood Spaces: opportunities for outdoor play?” European early childhood education research journal, 18 (4), 437-443, 2010.

[11] Bilton, H., Outdoor learning in the early years. Management and innovation. 3rd ed, Routledge, Abingdon, 2010.

[12] Harms, T., Clifford, R.M. and Cryer, D., Early childhood environment rating scale, revised ed, Teachers College Press, New York, 2005.

[13] Sylva, K., Siraj-Blatchford, I., Taggart, B., Sammons, P., Melhuish, E., Elliot, K., and Totsika, V., "Capturing Quality in Early Childhood Through Environmental Rating Scales," Early childhood research quarterly, 21, 76-92, 2006.

[14] Sylva, K., Siraj-Blatchford, I., and Taggart, B., Assessing quality in the early years. Early childhood environment rating scale (ECERS-E), Trentham Books Ltd, Stoke on Trent, 2006.

[15] Bruce, T., Early childhood education, 3rd ed, Hodder Arnold, London, 2005.

[16] Curtis, A., A curriculum for the pre-school child. Learning to learn, NFER-Nelson, Windsor, 1986.

[17] Edgington, M., The great outdoors. Developing children's learning through outdoor provision, 2nd ed, British Association for Early Childhood Education, London, 2003.

[18] Garrick, R., Playing outdoors in the early years, 2nd ed, Continuum International Publishing Group, London, 2009.

[19] Ouvry, M., Exercising muscles and minds: Outdoor play and the early years curriculum, The National Early Years Network, London, 2003.

[20] Cusden, P., The English nursery school, Kegan Paul, Trench, Trubner, London, 1938.
[21] de Lissa, L., Life in the Nursery School, Longmans, Green and Co, London, 1939.

[22] Isaacs, S., The nursery years. The mind of the child from birth to six years, Routledge and Kegan Paul Ltd, London, 1929.

[23] McMillan, M., The nursery school, Dent and Sons, London, 1930.

[24] Owen, G., Nursery school education, Methuen, London, 1928.

[25] Lasenby, M., The early years. A curriculum for young children. Outdoor play, Harcourt Brace Jovanovich, London, 1990.

[26] Simmons, R., "Questionnaires.” In Researching Social Life, 3rd ed., edited by N. Gilbert, 3rd ed. Sage Publications Limited, London, 182-205, 2008.

[27] Department for Education, Statutory framework for early years foundation stage, Department for Education, London, 2014.

[28] Hodkinson, P., "Grounded theory and inductive research 3rd ed", In Researching social life, edited by Gilbert, N., Sage Publications Ltd, London, 2008, 80-100.

[29] Bilton, H., The Aims of Early Years Outdoor Education in England: a Conceptual and Empirical investigation. University of Reading. 2014.

[30] Alexander, R., ed. Children, their world, their education. Final report and recommendations of the Cambridge primary review, Routledge, Abingdon, 2010.

[31] Sandseter, E., "Children's expression of exhilaration and fear in risky play,” Contemporary issues in early childhood 10 (2), 92106, 2009a.

[32] Sandseter, E.. "Characteristics of Risky Play." Journal of adventure education and outdoor learning, 9 (1), 3-21, $2009 \mathrm{~b}$.

[33] Stephenson, A., "Opening up the outdoors: exploring the relationship between the indoor and outdoor environments of a centre,” European early childhood research journal, 10 (1), 29-38, 2002

[34] Van Der Eyken, W., The pre- school years, Penguin, Harmondsworth, 1977.

[35] Bilton, H., The development and significance of the nursery garden and outdoor play, Unpublished MA dissertation, University of Surrey, 1989.

[36] McNee, D., "Outdoor Play in the Nursery- a Neglected Area?" Early Years, 4 (2), 16-25, 1984. 